\title{
Polymorphisms of the MMP-9 gene and abdominal aortic aneurysm
}

\author{
Linda Smallwood ${ }^{1}$, Richard Allcock ${ }^{2}$, Frank van Bockxmeer ${ }^{2}$, Nicole Warrington ${ }^{3}$, Lyle J \\ Palmer $^{3}$, Barry lacopetta ${ }^{1}$, Jonathan Golledge ${ }^{4}$, and Paul E Norman ${ }^{1}$ \\ ${ }^{1}$ School of Surgery, University of Western Australia. \\ 2 School of Pathology and Laboratory Medicine, University of Western Australia. \\ ${ }^{3}$ Centre for Genetic Epidemiology and Biostatistics, University of Western Australia. \\ ${ }^{4}$ The Vascular Biology Unit, School of Medicine, James Cook University, Townsville, \\ Queensland, Australia
}

\begin{abstract}
Background-Increased matrix metalloproteinase-9 (MMP-9) activity has been implicated in the formation of abdominal aortic aneurysms (AAAs). The aim of the present study was to explore the association between potentially functional variants of the MMP-9 gene and AAA.

Method-The $-1562 \mathrm{C}>\mathrm{T}$ and $-1811 \mathrm{~A}>\mathrm{T}$ variants of the MMP-9 gene were genotyped in 678 men with AAAs ( $>30 \mathrm{~mm}$ in diameter) and 659 controls (aortic diameter 19-22mm) recruited from a population-based trial of screening for AAAs. The levels of MMP-9 were measured in a random subset of 300 cases and 84 controls. The association between genetic variants (including haplotypes) and AAA was assessed using multivariate logistic regression.
\end{abstract}

Results-There was no association between the MMP-9 - 1562C>T (OR $0.7095 \% \mathrm{CI} 0.27,1.82$ ) or $-1811 \mathrm{~A}>\mathrm{T}$ (OR $0.71,95 \% \mathrm{CI} 0.28,1.85$ ) genotypes, or the most common haplotype (OR 0.81 $95 \%$ CI $0.62,1.05)$, and AAA. The serum MMP-9 concentration $(\mathrm{ng} / \mathrm{mL})$ was higher in cases than controls and in minor allele carriers in cases and controls although the differences were not statistically significant.

Conclusion-The results suggest that a genetic tendency to have higher levels of circulating MMP-9 is not associated with AAAs.

\section{Introduction}

Proteolysis is a key process in the development of abdominal aortic aneurysms (AAAs). Although various matrix metalloproteinases (MMPs) have been implicated in the pathogenesis of AAA, one of the most important appears to be MMP-9 (92 kD type IV collagenase) 1, 2. MMP-9 is expressed in the walls of AAAs and the level increases with diameter 1, 3 and in the event of rupture 4. Circulating levels of MMP-9 appear to be elevated in aneurysmal disease 5 and may be associated with both the rate of expansion 6 and with rupture 7. Aneurysm formation is inhibited in MMP-9-deficient mice models 8, 9 and there is evidence of differential expression of MMP-9 in the abdominal aorta 10.

Although the walls of aneurysmal aortas may be a source of MMP-9 5, it is not known if upregulation of MMP-9 initiates the onset of AAA formation or is part of the response to the

Author for Correspondence: Paul Norman School of Surgery, University of Western Australia Fremantle Hospital, PO Box 480, Fremantle, WA 6959, Australia. Tel: +61 894313333 Fax: +61 894312623 paul.norman@uwa.edu.au. 
disease (ie reverse causation). As MMP-9 activity may be under genetic control 11, its role in the causal pathway can be explored by comparing the frequency of genetic variants associated with increased MMP-9 activity in subjects with and without AAAs. Functional variants of the MMP-9 gene (specifically $-1562 \mathrm{C}>\mathrm{T}$ ) have been implicated in AAA in some but not all studies 12,13 . The aim of the present study was to explore the association between two single nucleotide polymorphisms (SNPs) of the MMP-9 gene $(-1562 \mathrm{C}>\mathrm{T}$ and $-1811 \mathrm{~T}>\mathrm{A}$ ) and AAA in a large population-based cohort. These SNPs were chosen as they are located in the promoter region of the MMP-9 gene, and therefore have the potential to influence MMP-9 activity 11.

\section{Methods}

\section{Subject recruitment}

Details of the Western Australian trial of screening for AAAs are described elsewhere 14, 15. Men attending for screening completed a cardiovascular risk factor questionnaire. Height, weight, girth at hips and waist, and blood pressure were measured. The maximum diameter of the infra-renal aorta was measured using a Capasee ultrasound machine with a $3.75 \mathrm{MHz}$ probe (Toshiba Australia, North Ryde, NSW). All staff performing ultrasound measurements participated in regular quality control exercises and $95 \%$ of differences between repeat measures were less than $3 \mathrm{~mm}$.

Between 1996 and 1998, 12,203 men aged 65-83 years attended for baseline screening and 875 with AAAs (aortic diameters $>30 \mathrm{~mm}$ ) were identified. Men with large AAAs (generally $>50 \mathrm{~mm}$ ) were referred for surgical assessment and were not actively recruited into surveillance and follow-up. All men with small AAAs (aortic diameter 30-50mm) were invited to attend a follow-up study (1997-2004) involving repeat ultrasound scans at intervals of 6-12 months 16. At the first follow-up visit, a sample of blood was obtained from all consenting men. Men without AAAs were reviewed as part of a separate study in 2001-4 which also included blood sampling 17. The controls for the study consisted of randomly selected age-matched men with aortic diameters in a previously defined reference range of 19-22mm 18. The study was approved by the Human Research Ethics Committee of the University of Western Australia.

\section{Laboratory Methods}

Genomic DNA was extracted from whole blood using a standard Triton X-100 procedure. Two SNPs in the MMP-9 promoter region were chosen for study: MMP-9 -1562 C>T (rs3918242) was selected on the basis that it may affect MMP-9 mRNA levels 11; MMP-9 $-1811 \mathrm{~T}>\mathrm{A}$ (rs3918241) also lies in the promoter region, although its effect on mRNA expression has not been formally examined. Both SNPs are found at $>10 \%$ frequency in the Caucasian population (dbSNP; http://www.ncbi.nlm.nih.gov/SNP). MMP-9 -1562 was genotyped using restriction-fragment length polymorphism analysis. MMP9 -1811 was genotyped using fluorescent Taqman probes (Applied Biosystems). Aliquoted serum collected during follow-up was stored at $-80^{\circ} \mathrm{C}$, as previously described19, 20. Thawed serum was analysed at completion of the study using ELISA to measure MMP-9 concentrations in a randomly selected subset of 300 cases and 84 controls (Duoset, R\&D Systems). Inter-assay coefficient of variations were between 3 and $6 \%$.

\section{Statistical Methods}

The primary binary outcome of this association analysis is the presence or absence of AAA (aortic diameter $>30 \mathrm{~mm}$ ). The principal explanatory variables are the two polymorphisms from the MMP-9 gene, $-1562 \mathrm{C}>\mathrm{T}$ and $-1811 \mathrm{~T}>\mathrm{A}$. All loci were tested for deviations from Hardy-Weinberg equilibrium by means of an exact test, using only controls. Univariate 
logistic regression was initially used to model the effects of genotype on AAA case-control status. This was followed by multivariate analyses, with independent variables selected via step-wise regression based on prior evidence of their involvement in AAA development. Only those covariates that were statistically significant predictors of the outcome were retained for multivariate modelling. The two bi-allelic MMP-9 polymorphisms were then sequentially added under a co-dominant model coded into three classes, with the most common homozygote as the baseline. Further genetic modelling (dominant, recessive or additive) was then guided by the coefficients for the co-dominant model.

Haplotypes were inferred using the Expectation Maximization (EM) algorithm 21and a global test of haplotype association was initially performed taking the most common haplotype as baseline and comparing all other haplotypes simultaneously. Any haplotypes that showed statistical significance in this analysis were then explored individually. All analyses and haplotype estimations were performed under a generalized linear model framework 22.

Natural logarithmic transformations of MMP-9 serum concentrations were undertaken to ensure that residuals were approximately Normally distributed in regression models. Linear regression was used to assess the association between genotype and $\log _{\mathrm{e}}$ MMP-9, which is presented as a geometric mean comparing those who were herterozygotes or minor allele homozygotes for the two MMP-9 genotypes to major allele homozygotes. R and SimHap were used to manage and analyse the data 23,24 . Statistical significance was defined at the $5 \%$ level.

\section{Results}

Genotyping results were available from 678 cases, representing $77 \%$ of the 875 men found to have AAAs at baseline screening. There were 535 men with AAAs between $30-39 \mathrm{~mm}$ in diameter, 118 between $40-49 \mathrm{~mm}, 25$ of $50+\mathrm{mm}$ and 659 controls (aortic diameters between 19-22mm). The characteristics and risk factors of the cases and controls are shown in Table 1. Genotyping was successful in the following percentages of cases and controls respectively: MMP-9 -1562 C>T (97.4\%, 98.2\%) and MMP-9 -1811 A > T (96.3\%, 98.9\%). Genotype frequencies in cases and controls are presented in Table 2. Both SNPs in control subjects were in Hardy-Weinberg equilibrium.

There was no association (OR $0.70,95 \% \mathrm{CI} 0.27,1.82)$ between the MMP-9 $-1562 \mathrm{C}>\mathrm{T}$ variant and AAA in the multivariate modelling (Table 3). Exclusion of the 25 men with larger AAAs (>50mm) did not alter this result substantially (OR 0.66, 95\% CI $0.25,1.77$ ). Similar modelling also revealed no association with MMP-9 - 1811A $>$ T (OR 0.71, 95\%CI $0.28,1.85$ ). Using the most common halplotype (h.TC) as a reference, there was no evidence of an association between remaining haplotypes and AAA (Table 4).

The serum MMP-9 concentration $(\mathrm{ng} / \mathrm{mL})$ was higher in cases than controls although the difference was not statistically significant $(\mathrm{P}=0.12)$ : geometric mean 750.2 (95\% CI 707.2, 795.7) in cases $(n=300)$ and 681.1 $(95 \%$ CI 617.7, 751.0) in controls $(n=84)$. The geometric mean serum MMP-9 concentrations were not significantly different across genotypes in either cases or controls for either SNP, in both a univariate and multivariate modelling framework (Table 5).

\section{Discussion}

This study has found no evidence of an association between the putatively functional MMP-9 - $1562 \mathrm{C}>\mathrm{T}$ variant and screen-detected small AAAs in men. In addition no association was found with another promotor gene variant (MMP-9 -1811A>T) or with 
haplotypes of these SNPs. There was a non-significant trend towards higher levels of MMP-9 in the minor allele carriers for both SNPs - and in men with AAAs.

There is ample evidence that MMP-9 is important in the pathogenesis of AAAs. MMP-9 activity is up-regulated in the walls of AAAs, particularly large AAAs and at the site of rupture $1,2,4,25$. Various animal model studies also support a key role for MMP-9 in aneurysm formation $8^{-10}$. Several studies have documented elevated levels of circulating MMP-9 in patients with AAAs 5, 26, 27. Reports that levels fall after successful endoluminal stenting of AAAs is further indirect evidence that MMP-9 activity is upregulated in AAAs 28, 29.

Although the animal model studies support a causal role for MMP-9 in aneurysmal disease, observational studies in humans based on analyses of MMP-9 levels in the aortic wall or the circulation are subject to residual confounding and reverse causation. The advantage of genetic studies is that they minimise this problem as genotype precedes adult pathology. The present study focussed on the MMP-9 $-1562 \mathrm{C}>\mathrm{T}$ variant as it appears to be of functional significance. In vitro studies have shown that the T allele of MMP-9 $-1562 \mathrm{C}>\mathrm{T}$ results in higher promoter activity as a transcription repressor is preferentially bound to the $\mathrm{C}$ allele 11. The variant is associated with up-regulation of MMP-9 RNA and protein in the aortic wall and increased stiffness of large arteries 30.

In a study of 414 cases of AAA and 203 controls, Jones et al initially reported a significant association (OR 2.41, 95\%CI 1.44,4.02) between the T allele of MMP-9 $1562 \mathrm{C}>\mathrm{T}$ and AAA 12. A subsequent study involving two separate populations (involving a total of 387 cases and 425 controls) failed to confirm this result 13. In another study of 455 patients with small AAAs, there was no association between the $\mathrm{T}$ allele and rate of expansion 31 . Although a recent meta-analyses of these studies suggested a marginally positive association (OR $1.09,95 \%$ CI $1.10,1.18)$ this was probably due to the weighting $(57.8 \%)$ of the study by Jones et al 32 .

The strengths of this study are its relatively large sample size and the use of an age-matched controls who have all had an ultrasound scan to exclude an AAA. Furthermore it is the only study of AAA to include an assessment of both MMP-9 genotype and protein concentration. The negative result may be due to the relatively small influence of both SNPs on MMP-9 levels and the possibility of other unidentified variants playing a greater role. There is some evidence that MMP-9 may be particularly important in larger AAAs 1 and it is possible that a significant association would have been found if a greater proportion of large AAAs had been included. This was not possible as the cases were recruited from a population-based screening study rather than a selected surgical series. However the discovery of factors causing early disease remains a priority for our understanding of AAA formation and prevention and, as such, the study of small AAAs is relevant.

The findings of this study should not be interpreted as evidence against the role of MMP-9 as either a biomarker or a proteolytic mediator in aneurysmal disease. However, the results do suggest that a genetic tendency to have higher levels of circulating MMP-9 is not associated with AAAs.

\section{Acknowledgments}

Special thanks to all men and staff who participated in the Western Australian Abdominal Aortic Aneurysm Program and the Health In Men Study. The research was supported by NIH Grant R01 HL080010-01 and NHMRC Project Grant 303232. PN and JG are supported by NHMRC Practitioner Fellowships 458505 and 431503.

Funding: NHMRC \&NIH 


\section{References}

1. Freestone T, Turner RJ, Coady A, Higman DJ, Greenhalgh RM, Powell JT. Inflammation and matrix metalloproteinases in the enlarging abdominal aortic aneurysm. Arterioscler Thromb Vasc Biol. 1995; 15:1145-1151. [PubMed: 7627708]

2. Sakalihasan N, Delvenne P, Nusgens BV, Limet R, Lapiere CM. Activated forms of $\mathrm{MMP}_{2}$ and $\mathrm{MMP}_{9}$ in abdominal aortic aneurysms. J Vasc Surg. 1996; 24:127-133. [PubMed: 8691515]

3. McMillan WD, Tamarina NT, Cipollone M, Jonson DA, Parker MA, Pearce WH. Size matters: the relationship between MMP-9 expression and aortic diameter. Circulation. 1997; 96:2228-2232. [PubMed: 9337194]

4. Petersen E, Gineitis A, Wagberg F, Andgquist K-A. Activity of matrix metalloproteinase-2 and -9 in abdominal aortic aneurysms. Relation to size and rupture. Eur J Vasc Endovasc Surg. 2000; 20:457-461. [PubMed: 11112465]

5. McMillan WD, Pearce WH. Increased plasma levels of metalloproteinase-9 are associated with abdominal aortic aneurysms. J Vasc Surg. 1999; 29:122-129. [PubMed: 9882796]

6. Lindholt JS, Vammen S, Fasting H, Henneberg EW, Heickendorff L. The plasma level of matrix metalloproteinase 9 may predict the natural history of small abdominal aortic aneurysms. A preliminary study. Eur J Vasc Endovasc Surg. 2000; 20:281-285. [PubMed: 10986027]

7. Wilson WRW, Anderton M, Choke EC, Dawson J, Loftus I, Thompson MM. Elevated plasma MMP1 and MMP9 are associated with abdominal aortic aneurysm rupture. Eur J Vasc Endovasc Surg. 2008; 35:580-584. [PubMed: 18226564]

8. Pyo R, Lee JK, Shipley JM, Curci JA, Mao D, Ziporin SJ, et al. Targeted gene disruption of metalloproteinase-9 (gelatinase B) suppresses development of experimental abdominal aortic aneurysms. J Clin Invest. 2000; 105:1641-1649. [PubMed: 10841523]

9. Longo GM, Xiong W, Greiner TC, Zhao Y, Fiotti N, Baxter BT. Matrix metalloproteinases 2 and 9 work in concert to produce aortic aneurysms. J Clin Invest. 2002; 110:625-632. [PubMed: 12208863]

10. Ailawadi G, Knipp BS, Lu G, Roelfs KJ, Ford JW, Hannawa KK, et al. A nonintrinsic regional basis for increased infrarenal aortic MMP-9 expression and activity. J Vasc Surg. 2003; 37:10591066. [PubMed: 12756355]

11. Zhang B, Shu Y, Herrmann S-M, Eriksson P. Functional polymorphism in the regulatory region of gelatinase (Beta) gene in relation to severity of coronary atherosclerosis. Circulation. 1999; 99:1788-1794. [PubMed: 10199873]

12. Jones GT, Phillips LV, Harris EL, Rossaak JI, van Rij AM. A functional matrix metalloproteinase 9 polymorphism (C-1562T) is associated with abdominal aortic aneurysm. J Vasc Surg. 2003; 38:1363-1367. [PubMed: 14681642]

13. Ogata T, Shibamura H, Tromp G, Sinha M, Goddard KAB, Sakalihasan N, et al. Genetic analysis of polymorphisms in biologically relevant candidate genes in patients with abdominal aortic aneurysms. J Vasc Surg. 2005; 41:1036-1042. [PubMed: 15944607]

14. Jamrozik K, Norman PE, Spencer CA, Parsons RW, Tuohy R, Lawrence-Brown MM, Dickinson JA. Screening for abdominal aortic aneurysms: lessons from a population-based study. Med J Aust. 2000; 173:345-350. [PubMed: 11062788]

15. Norman PE, Jamrozik K, Lawrence-Brown MM, Le M, Spencer CA, Tuohy R, Parsons R, Dickinson J. Population-based randomised controlled trial on impact of screening on mortality from abdominal aortic aneurysm. BMJ. 2004; 329:1259-1262. [PubMed: 15545293]

16. Norman PE, Spencer CA, Lawrence-Brown MM, Jamrozik K. C-reactive protein levels and the expansion of screen-detected abdominal aortic aneurysms in men. Circulation. 2004; 110:862866. [PubMed: 15302791]

17. Le MTQ, Jamrozik K, Davis TME, Norman PE. Negative association between infra-renal aortic diameter and glycaemia: The Health In Men Study. Eur J Vasc Endovasc Surg. 2007; 33:599-604. [PubMed: 17307366]

18. Norman PE, Le MTQ, Pearce C, Jamrozik K. Infra-renal aortic diameter predicts all-cause mortality. Arterioscler Thromb Vasc Biol. 2004; 24:1278-1282. [PubMed: 15130915] 
19. Norman PE, Flicker L, Almeida OP, Hankey GJ, Hyde Z, Jamrozik K. Cohort Profile: The Health In Men Study (HIMS). Int J Epidemiol. 2008 In Press.

20. Golledge J, Muller J, Shephard N, Clancy P, Smallwood L, Moran C, Dear A, Palmer LJ, Norman PE. Association between osteopontin and human abdominal aortic aneurysm. Arterioscler Thromb Vasc Biol. 2007; 27:655-660. [PubMed: 17170369]

21. Excoffier L, Slatkin M. Maximum likelihood estimation of molecular haplotype frequencies in a diploid population. Mol Biol Evol. 1995; 12:921-927. [PubMed: 7476138]

22. Dobson, J. An Introduction to Generalized Linear Models. Second edn. Chapman \& Hall/CRC; 2001.

23. http://www.genepi.org.au/simhap. http://www.genepi.org.au/simhapSimHap (v2.1 Beta): A comprehensive modelling framework and a simulation based approach to haplotypic analysis of population based data.

24. Ihaka R, Gentleman R. R: a language for data analysis and graphics. J Comput Graph Statist. 1996; 5:299-314.

25. Wilson WRW, Anderton M, Schwalbe EC, Jones LJ, Furness PN, Bell PRF, Thompson MM. Matrix metalloproteinase- 8 and -9 are increased at the site of abdominal aortic aneurysm rupture. Circulation. 2006; 113:438-445. [PubMed: 16432074]

26. Hovsepian DM, Ziporin SJ, Sakurai MK, Lee JK, Curci JA, Thompson RW. Elevated plasma levels of matrix metalloproteinase- 9 in patients with abdominal aortic aneurysms: a circulating marker of degenerative aneurysm disease. JVIR. 2000; 11:1345-1352. [PubMed: 11099248]

27. van Laake LW, Vainas T, Dammers R, Kitslaar PJEHM, Hoeks APG, Schurink GWH. Systemic dilation diathesis in patients with abdominal aortic aneurysms: a role for matrix metalloproteinase-9. Eur J Vasc Endovasc Surg. 2005; 29:371-377. [PubMed: 15749037]

28. Sangiogi G, D'Averio R, Mauriello A, Bondio M, Pontillo M, Castelvecchio S, et al. Plasma levels of metalloproteinases-3 and -9 as markers of successful abdominal aortic aneurysm exclusion after endovascular graft treatment. Circulation. 2001; 104(Suppl I):I-288-I-295. [PubMed: 11568071]

29. Lorelli DR, Jean-Claude JM, Fox CJ, Clyne J, Cambria RA, Seabrook GR, Towne JB. Response of plasma matrix metalloproteinase-9 to conventional abdominal aortic aneurysm repair or endovascular exclusion: implications for endoleak. J Vasc Surg. 2002; 35:916-922. [PubMed: 12021707]

30. Medley TL, Cole TJ, Dart AM, Gatzka CD, Kingwell BA. Matrixmetalloproteinase-9 genotype influences large artery stiffness through effects on aortic gene and protein expression. Arterioscler Thromb Vasc Biol. 2004; 24:1479-1484. [PubMed: 15191941]

31. Eriksson P, Jormsjo-Pettersson S, Brady AR, Deguchi H, Hamsten A, Powell JT. Genotypephenotype relationships in an investigation of the role of proteases in abdominal aortic aneurysm expansion. Br J Surg. 2005; 92:1372-1376. [PubMed: 16082623]

32. Thompson AR, Drenos F, Hafez H, Humphries SE. Candidate gene association studies in abdominal aortic aneurysm disease: a review and meta-analysis. Eur J Vasc Endovasc Surg. 2008; 35:19-30. [PubMed: 17920311] 
Table 1

Baseline characteristics of the AAA cases and the controls. Age, height, weight, BP and diameter are all expressed as means $\pm 1 \mathrm{SD}$. Remaining variables are percentages (number).

\begin{tabular}{|c|c|c|c|}
\hline & & $\mathbf{A A A}(n=678)$ & Controls $(n=659)$ \\
\hline Age (years) & & $73.3(4.4)$ & $72.3(3.9)$ \\
\hline Aortic diameter (mm) & & $35.7(6.8)$ & $21.2(1.1)$ \\
\hline BMI & & $27.2(3.7)$ & $26.6(3.2)$ \\
\hline \multirow[t]{2}{*}{ Waist Hip Ratio } & $<1.00$ & $66.5(451)$ & $75.7(499)$ \\
\hline & $\geq 1.00$ & $33.5(227)$ & $24.3(160)$ \\
\hline Systolic BP (mmHg) & & $157.1(22.0)$ & $155.0(19.4)$ \\
\hline Diastolic BP (mmHg) & & $90.8(12.2)$ & $89.9(10.8)$ \\
\hline \multirow[t]{4}{*}{ Place of Birth } & Australia & $57.7(391)$ & $63.7(420)$ \\
\hline & Northern Europe & $29.2(198)$ & $26.3(173)$ \\
\hline & Mediterranean & $6.0(41)$ & $4.4(29)$ \\
\hline & Other & $7.1(48)$ & $5.6(37)$ \\
\hline History of stroke & & $10.9(74)$ & $4.9(32)$ \\
\hline History of myocardial infarction & & $26.4(179)$ & $8.5(56)$ \\
\hline History of diabetes & & $9.9(67)$ & $5.8(38)$ \\
\hline History of coronary artery surgery & & $15.9(108)$ & $5.9(39)$ \\
\hline Father had AAA & & $1.8(12)$ & $1.1(7)$ \\
\hline History of/treatment for hypertension & & $53.4(362)$ & $35.5(234)$ \\
\hline History of/treatment for angina & & $29.6(201)$ & $13.1(86)$ \\
\hline History of/treatment for high cholesterol & & $44.1(299)$ & $31.6(208)$ \\
\hline \multirow[t]{4}{*}{ Smoking Status } & Never smoked & $14.5(98)$ & $36.1(238)$ \\
\hline & Ex-smoker & $67.7(459)$ & $54.6(360)$ \\
\hline & Current smoker $<25 /$ day & $10.3(70)$ & $5.6(37)$ \\
\hline & Current smoker $\geq 25 /$ day & $7.5(51)$ & $3.6(24)$ \\
\hline Vigorous exercise & & $19.9(135)$ & $31.1(205)$ \\
\hline Non-vigorous exercise & & $63.4(430)$ & $70.4(464)$ \\
\hline
\end{tabular}




\section{Alternative Table 1A}

Baseline characteristics of the AAA cases and the controls. Age, height, weight, BP and diameter are all expressed as means $\pm 1 \mathrm{SD}$. Remaining variables are percentages (number). T-test and chi-square tests were used to compare continuous and binary/categorical variables respectively.

\begin{tabular}{|c|c|c|c|c|}
\hline & & AAA $(n=678)$ & Controls $(n=659)$ & P-Value \\
\hline Age (years) & & $73.3(4.4)$ & $72.3(3.9)$ & $<0.001$ \\
\hline Aortic diameter (mm) & & $35.7(6.8)$ & $21.2(1.1)$ & $<0.001$ \\
\hline BMI & & $27.2(3.7)$ & $26.6(3.2)$ & 0.002 \\
\hline \multirow[t]{2}{*}{ Waist Hip Ratio } & $<1.00$ & $66.5(451)$ & $75.7(499)$ & $<0.001$ \\
\hline & $\geq 1.00$ & $33.5(227)$ & $24.3(160)$ & \\
\hline Systolic BP (mmHg) & & $157.1(22.0)$ & $155.0(19.4)$ & 0.06 \\
\hline Diastolic BP (mmHg) & & $90.8(12.2)$ & $89.9(10.8)$ & 0.16 \\
\hline \multirow[t]{4}{*}{ Place of Birth } & Australia & $57.7(391)$ & $63.7(420)$ & 0.13 \\
\hline & Northern Europe & $29.2(198)$ & $26.3(173)$ & \\
\hline & Mediterranean & $6.0(41)$ & $4.4(29)$ & \\
\hline & Other & $7.1(48)$ & $5.6(37)$ & \\
\hline History of stroke & & $10.9(74)$ & $4.9(32)$ & $<0.001$ \\
\hline History of myocardial infarction & & $26.4(179)$ & $8.5(56)$ & $<0.001$ \\
\hline History of diabetes & & $9.9(67)$ & $5.8(38)$ & 0.008 \\
\hline History of coronary artery surgery & & $15.9(108)$ & $5.9(39)$ & $<0.001$ \\
\hline Father had AAA & & $1.8(12)$ & $1.1(7)$ & 0.46 \\
\hline History of/treatment for hypertension & & $53.4(362)$ & $35.5(234)$ & $<0.001$ \\
\hline History of/treatment for angina & & $29.6(201)$ & $13.1(86)$ & $<0.001$ \\
\hline History of/treatment for high cholesterol & & 44.1 (299) & $31.6(208)$ & $<0.001$ \\
\hline \multirow[t]{4}{*}{ Smoking Status } & Never smoked & $14.5(98)$ & $36.1(238)$ & $<0.001$ \\
\hline & Ex-smoker & $67.7(459)$ & $54.6(360)$ & \\
\hline & Current smoker $<25 /$ day & $10.3(70)$ & $5.6(37)$ & \\
\hline & Current smoker $\geq 25 /$ day & $7.5(51)$ & $3.6(24)$ & \\
\hline Vigorous exercise & & $19.9(135)$ & $31.1(205)$ & $<0.001$ \\
\hline Non-vigorous exercise & & $63.4(430)$ & $70.4(464)$ & 0.008 \\
\hline
\end{tabular}


Table 3

Results of the multivariate modelling including the MMP-9 1562 C>T genotype.

\begin{tabular}{|c|c|c|}
\hline Variable & & OR $(95 \% \mathrm{CI})$ \\
\hline Age (yrs) & & $1.08(1.04,1.11)$ \\
\hline Waist Hip Ratio & & $1.45(1.09,1.93)$ \\
\hline Diastolic BP (mmHg) & & $1.02(1.00,1.03)$ \\
\hline History stroke & & $1.88(1.12,3.14)$ \\
\hline History myocardial infarction & & $2.88(1.94,4.29)$ \\
\hline History coronary artery surgery & & $2.34(1.48,3.68)$ \\
\hline History of /treatment for hypertension & & $1.60(1.23,2.09)$ \\
\hline \multirow[t]{4}{*}{ Smoking status } & Never Smoked & --------- \\
\hline & Ex-smoker & $3.21(2.33,4.42)$ \\
\hline & Current smoker $<25 /$ day & $5.54(3.20,9.61)$ \\
\hline & Current smoker $\geq 25 /$ day & $5.34(2.84,10.04)$ \\
\hline Vigorous exercise & & $0.53(0.39,0.72)$ \\
\hline Non-vigorous exercise & & $0.74(0.56,0.97)$ \\
\hline \multirow[t]{3}{*}{ MMP-9-1562 } & $\mathrm{CC}$ & --------- \\
\hline & $\mathrm{CT}$ & $0.80(0.60,1.09)$ \\
\hline & TT & $0.70(0.27,1.82)$ \\
\hline
\end{tabular}




\section{Table 4}

MMP-9 haplotypes and their association with AAA in multivariate modelling. All haplotypes with frequencies $<1 \%$ were grouped together in the rare category.

\begin{tabular}{ccccc}
\hline & 1811T $>$ A & 1562C $>$ T & Frequency & OR $(\mathbf{9 5 \%}$ CI $)$ \\
\hline h.TC & $\mathrm{T}$ & $\mathrm{C}$ & 0.837 & --- \\
h.AT & $\mathrm{A}$ & $\mathrm{T}$ & 0.151 & $0.81(0.62,1.05)$ \\
Rare & $\mathrm{C}$ & $\mathrm{T}$ & 0.013 & $0.91(0.49,1.68)$ \\
\hline
\end{tabular}




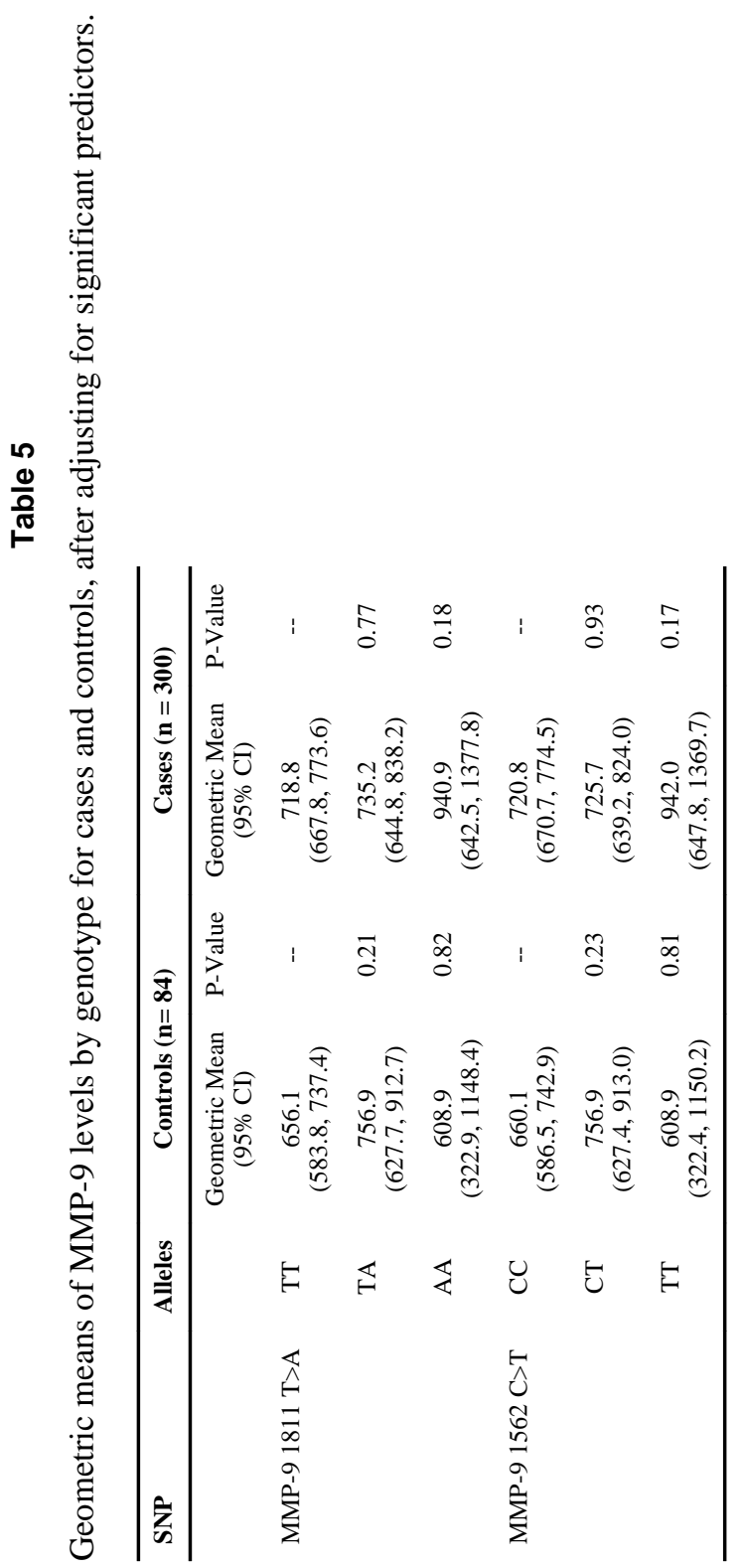

